\title{
An Investigation of Equilibrium Iron Thermochemistry in Flames
}

\author{
Susanne Staude* and Burak Atakan
}

Thermodynamik, IVG, Universität Duisburg-Essen, Lotharstr. 1, 47057 Duisburg, Germany

\begin{abstract}
The thermochemistry of iron in flames has been investigated theoretically using the Cantera software package. The focus was placed on the iron intermediates as well as the conditions under which condensed phases of iron or ironspecies could be expected in a flame. For this purpose, equilibrium calculations were carried out for iron seeded hydrogen/oxygen/argon and propene/oxygen/argon gas mixtures at combustion relevant conditions. Varying stoichiometries over a wide range of temperatures and pressures were investigated. The results allow a prognosis which gas phase iron species may be expected in measurable concentrations at given flame conditions, and also whether condensed phases of iron or iron species are likely. Also, the effect of sampling probes on the gas mixture composition due to flame cooling is discussed.
\end{abstract}

\section{INTRODUCTION}

In recent years there has been a renewed interest in the effect of iron-containing additives, such as iron pentacarbonyl $\left(\mathrm{Fe}(\mathrm{CO})_{5}\right)$ or ferrocene $\left(\mathrm{Fe}\left(\mathrm{C}_{5} \mathrm{H}_{5}\right)_{2}\right)$, on the behaviour of flames. Linteris et al. have investigated in some detail the effect of iron pentacarbonyl on the burning velocities of premixed and diffusion flames, both theoretically and experimentally [1-4]. In addition to the flame inhibiting effect of iron pentacarbonyl or ferrocene, current interest is moving towards the formation of condensed phases, soot or iron oxides. Hirasawa et al. [5] found that ferrocene addition reduced the critical sooting $\mathrm{C} / \mathrm{O}$ ratio of premixed ethylene flames. However, Kim et al. [6] found that although iron addition had a soot-enhancing effect early in the flame, it caused an overall reduction in soot emissions. This was explained with an increased rate of soot oxidation in the soot burnout regime of the flame.

$\mathrm{Fe}(\mathrm{CO})_{5}$ and ferrocene have also been investigated of late as precursors for nano-particles [7, 8] or carbon nano-tubes [9-11].

Both, for the investigation of the flame effects and also for the work on nano-particles, nozzle sampling techniques are frequently employed for subsequent analysis of the gases and/or particles using molecular beam or particle mass spectrometry (See, for example [12, 13]). Paur et al. [14] used a nozzle to produce a molecular beam which they later analysed using particle mass spectrometry. However, introducing a nozzle into the flame region also introduces a surface which is considerably cooler than the flame gases. This can lead to iron and/or iron oxide condensation on the nozzle, as was found by Tian et al. [15], and can thus complicate measurements of iron species in flames. This condensation may sometimes not occur without nozzle, so that data interpretation of studies using a sampling nozzle may get

*Address correspondence to this author at the Thermodynamik, IVG, Universität Duisburg-Essen, Lotharstr. 1, 47057 Duisburg, Germany; Tel: +49-203-3791558; Fax: +49-203-3791594;

E-Mail: susanne.staude@uni-due.de delicate. The current study focuses on the limiting case of thermodynamic equilibrium; this can give an indication of the conditions in which problems with condensation may be expected.

For this work, the thermochemistry of iron in flames has been investigated theoretically using the Cantera software package [16]. Previous equilibrium calculations, which do not span this wide range, can be found in $[4,17,18]$. The focus was placed on the iron intermediates as well as the conditions under which condensed phases of iron or ironspecies could be expected in a flame. It has to be emphasised that the species concentrations in a flame are clearly not only dependent on the thermodynamic equilibrium but also to a great extent on chemical kinetics. The latter are not considered here, so that great care has to be taken when the results of this study are to be used in the evaluation of a flame scenario. This is both true for the gas phase species as well as for the estimation of condensation. The kinetics governing condensation and, in particular, particle formation in irondoped flames are discussed in detail in $[19,20]$. However, in systems where surfaces are already present, as is the case with sampling nozzles, it is well known that condensed phases are much easier formed than in systems without, where large super-saturations are observed prior to condensation [21].

\section{SPECIFIC OBJECTIVES}

The objectives of this work were twofold. Firstly, equilibrium calculations help to understand which iron intermediates can be expected under flame conditions as a limiting case. This can aide in the design of experiments as well as the interpretation of experimental results.

Secondly, the temperature and pressure conditions under which condensed phase iron species can be expected in equilibrium were to be determined. This is also important information for experimenters working with iron doped flames. Deposition of condensed iron species on cooler parts of the combustion apparatus can gravely affect the measurement results if they are not accounted for. The choice of measurement technique will also be affected if condensed iron species may be expected [15]. 


\section{METHODOLOGY}

For this purpose, equilibrium calculations were carried out for iron seeded hydrogen/oxygen/argon and propene/ oxygen/argon gas mixtures at combustion relevant conditions, using the Cantera software package. Besides the gas phase iron species $\mathrm{FeC}_{5} \mathrm{O}_{5}, \mathrm{Fe}\left(\mathrm{C}_{5} \mathrm{H}_{5}\right)_{2}, \mathrm{FeO}, \mathrm{FeO}_{2}, \mathrm{FeH}$, $\mathrm{FeOH}, \mathrm{Fe}(\mathrm{O}) \mathrm{OH}$ and $\mathrm{Fe}(\mathrm{OH})_{2}$, the pure condensed phases of $\mathrm{Fe}, \mathrm{FeO}, \mathrm{Fe}(\mathrm{OH})_{2}, \mathrm{Fe}(\mathrm{OH})_{3}, \mathrm{Fe}_{2} \mathrm{O}_{3}$ and $\mathrm{Fe}_{3} \mathrm{O}_{4}$ were also included in the calculation. The gas phase thermochemistry data for $\mathrm{Fe}(\mathrm{OH})_{2}$ and $\mathrm{FeO}$ are taken from [22], for $\mathrm{Fe}(\mathrm{O}) \mathrm{OH}$ from [3] and for all other iron species as well as for the condensed species from the NASA thermodynamic database [23]. For both gas mixtures, calculations were carried out at three different stoichiometries: $\phi=0.37,1.0$, and 2.31. In each case $170 \mathrm{ppm}$ of iron pentacarbonyl or ferrocene were added. Temperatures were varied from $1100 \mathrm{~K}$ to $2500 \mathrm{~K}$ at pressures between 30 mbar and 10 bar.

\section{RESULTS AND DISCUSSION}

The results of the calculations are shown in Figs. (1 to 4). Only those iron species are shown that have concentrations
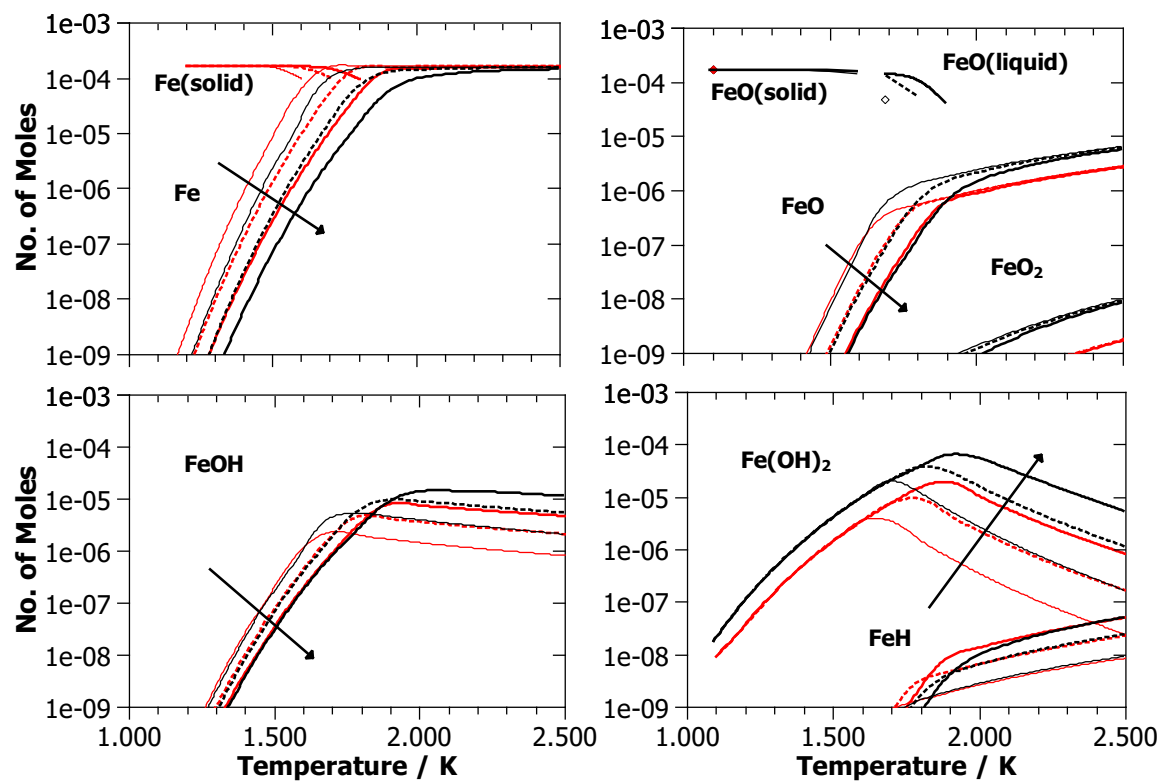

Fig. (1). Effect of fuel and pressure on iron species for fuel rich mixtures $(\phi=2.31)$ (red lines/symbols: $\mathrm{C}_{3} \mathrm{H}_{6}$, black lines/symbols: $\mathrm{H}_{2}$, thin line/empty symbol: $30 \mathrm{mbar}$, dashed line: $200 \mathrm{mbar}$, thick line/solid symbol: 1 bar. The arrows indicate the direction of increasing pressure).
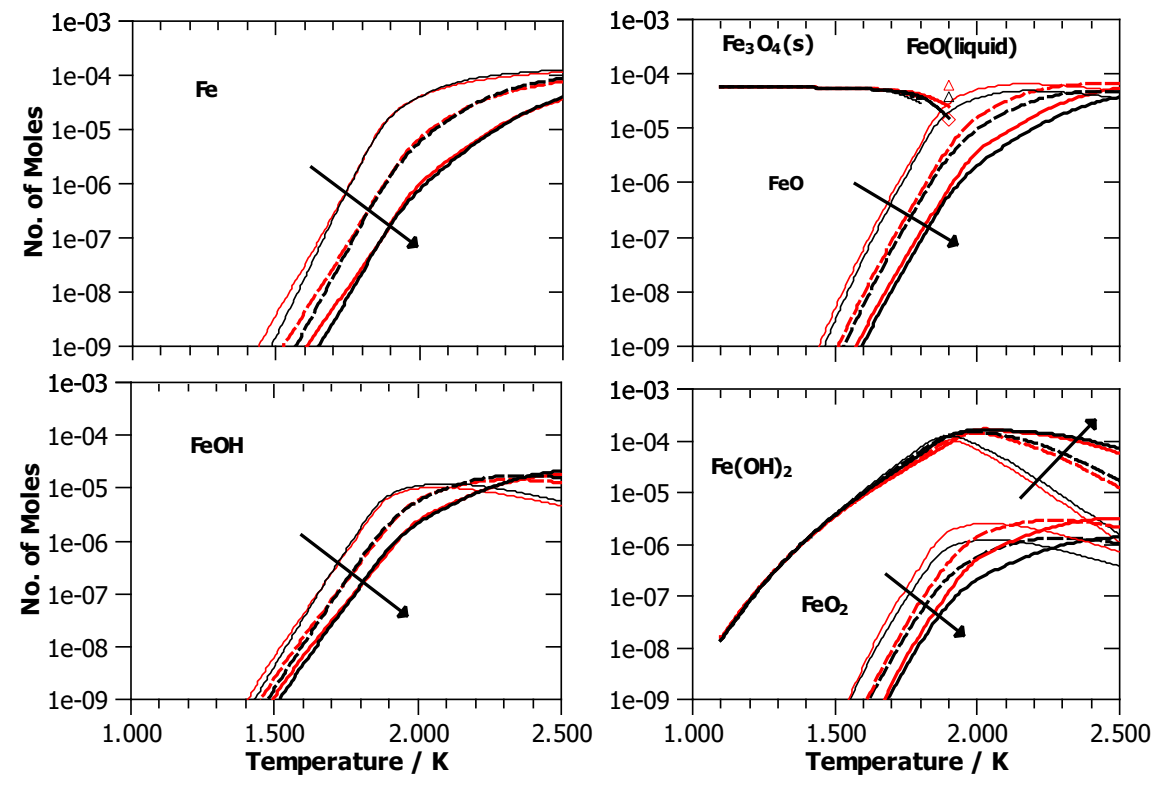

Fig. (2). Effect of fuel and pressure on iron species for stoichiometric mixtures (red lines/symbols: $\mathrm{C}_{3} \mathrm{H}_{6}$, black lines/symbols: $\mathrm{H}_{2}$, thin line/diamond: 30 mbar, dashed line/triangle: 200 mbar, thick line: 1 bar). 

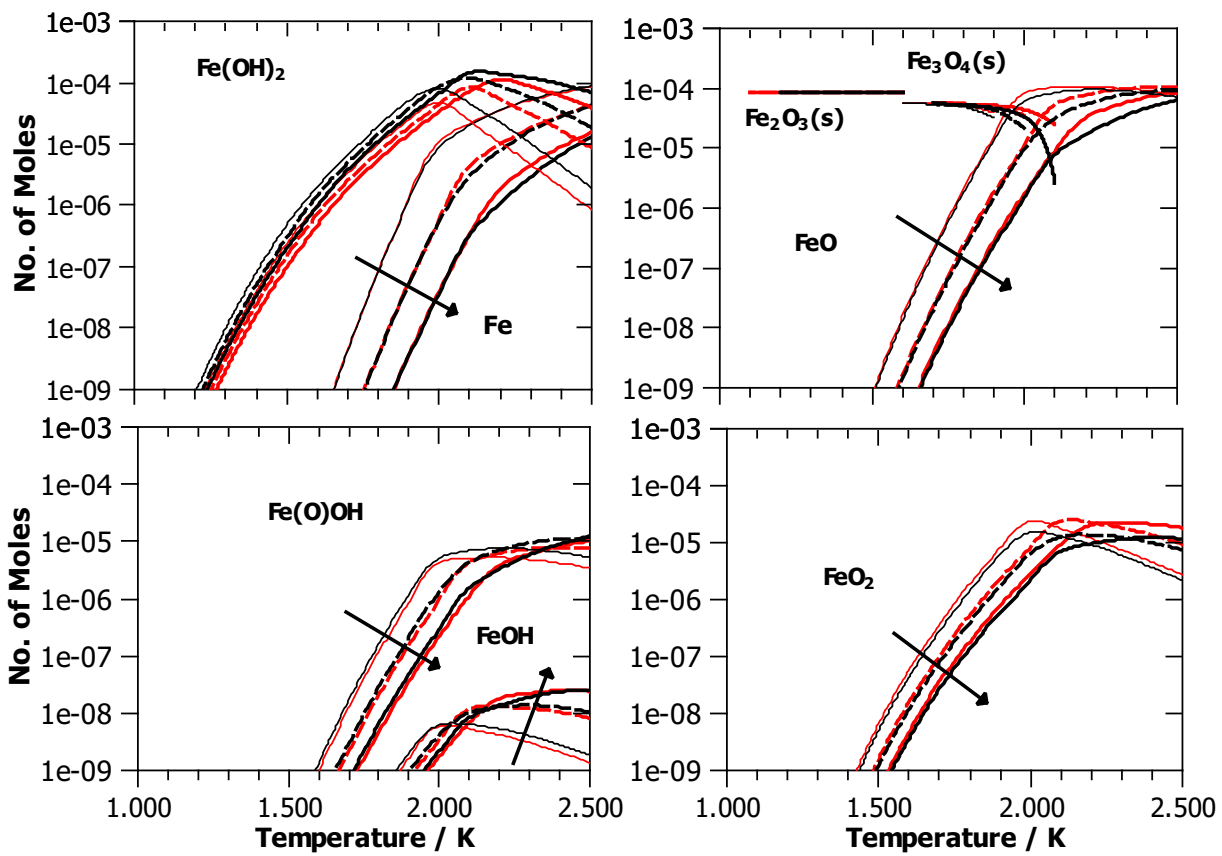

Fig. (3). Effect of fuel and pressure on iron species for lean mixtures $(\phi=0.37)$ (red lines/symbols: $\mathrm{C}_{3} \mathrm{H}_{6}$, black lines/symbols: $\mathrm{H}_{2}$, thin line/empty symbol: 30 mbar, dashed line: 200 mbar, thick line/solid symbol: 1 bar).

above $10^{-9}$ at the given temperatures. Not surprisingly, the source of the iron added (iron pentacarbonyl or ferrocene) did not have a significant impact on the equilibrium of the iron species, since such a small amount was added that the stoichiometry is not influenced noticeably. The different fuels, hydrogen and propene, were mainly studied to observe the influence of the hydrogen to carbon ratio in the mixture on the equilibrium concentrations of iron containing compounds.

Figs. (1, 2 and 3) summarise the results for fuel rich $(\phi=$ $2.31)$, stoichiometric and lean $(\phi=0.37)$ conditions, respectively. Fig. (1) shows the effect of pressure on the concentration of the various gas phase iron species for both fuels that were examined. As can be seen, increasing the pressure will shift the curves for the gas phase iron species towards higher temperatures.

Some difference can be seen when comparing the two fuels investigated, mainly under fuel rich conditions. For the propene, the solid iron phase occurring above $1100^{\circ} \mathrm{C}$ is atomic iron, whereas in the hydrogen system, condensed iron oxide is forming. This effect also explains the difference in the occurrence of gaseous atomic iron at temperatures below $1600 \mathrm{~K}$ (at $30 \mathrm{mbar}), 1700 \mathrm{~K}$ (200 mbar) or $1900 \mathrm{~K}$ (1 bar). In the presence of carbon, relatively large amounts of oxygen are bound as carbon dioxide and carbon monoxide. As can be seen from Figs. ( 2 and $\mathbf{3}$ ), the difference between the two fuels is much less pronounced in stoichiometric and lean mixtures, because more oxygen is available then.

At the fuel rich conditions, the iron tends towards atomic iron at higher temperatures. As more oxygen is available at stoichiometric conditions, $\mathrm{FeO}$ becomes another major specie in equilibrium at high temperatures, in particular at the lower pressures. Around $2000 \mathrm{~K}$, almost all iron exist in the form of $\mathrm{Fe}(\mathrm{OH})_{2}$. At the lower pressures this changes very quickly as the temperature is increased towards $\mathrm{Fe}$ and $\mathrm{FeO}$. As the pressure is increased, $\mathrm{Fe}(\mathrm{OH})_{2}$ remains the main iron species until temperatures of around $2200 \mathrm{~K}$ for 200 mbar and $2400 \mathrm{~K}$ for $1 \mathrm{bar}$. These findings correspond well to those of Linteris et al. [17]. The effect is similar in the lean mixture, although the thermodynamic equilibrium will tend towards $\mathrm{FeO}$ rather than $\mathrm{Fe}$ above $2000 \mathrm{~K}$.

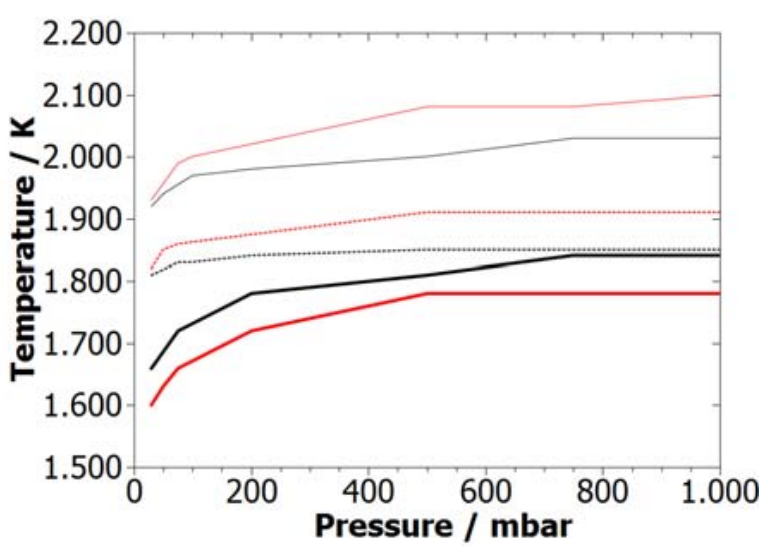

Fig. (4). Maximum temperature of condensed phase iron as a function of pressure, effect of stoichiometry and fuel (red: $\mathrm{C}_{3} \mathrm{H}_{6}$, black: $\mathrm{H}_{2}$, thick lines: $\phi=2.31$, dashed: $\phi=1$, thin: $\phi=0.37$ ).

Fig. (4) shows the temperatures below which condensed phases of iron species can be expected in equilibrium. As can be seen from the previous figures, this will be in the form of solid atomic iron for the fuel rich propene mixture and iron oxides $\left(\mathrm{FeO}, \mathrm{Fe}_{2} \mathrm{O}_{3}\right.$ or $\left.\mathrm{Fe}_{3} \mathrm{O}_{4}\right)$ for the fuel rich hydrogen mixture and the stoichiometric or lean mixtures of both fuels. Fig. (4) shows that of the iron species examined 
here, pure iron condenses in equilibrium at the lowest temperatures with $1600 \mathrm{~K}$ at $30 \mathrm{mbar}$. The occurrence of solid iron is most likely in oxygen-lean mixtures; as more oxygen is available the iron equilibrium will tend towards iron oxides, which will condense already at higher temperatures (from $1650 \mathrm{~K}$ at $30 \mathrm{mbar}$ to $1800 \mathrm{~K}$ at atmospheric pressure in the case of $\mathrm{FeO}$, and the other oxides at even higher temperatures).

Generally, it can be noted that the temperature below which condensed phases can be expected is reduced as the pressure is reduced.

Since the above observations are based on equilibrium calculations, they are not representative of the mixture composition near the flame front, even at the same temperature and pressure conditions. They can, however, give an indication of the species that could be expected in those regions of the combustion chamber where longer residence times of the gases are possible.

When a nozzle is used for sampling from a flame, for example to produce a molecular beam for gas phase mass spectrometry (e.g. [12]) or particulate sampling (as suggested by Roth [24]), the local temperature can be reduced drastically to well below the condensation temperatures. For quartz nozzles this temperature will be typically below 1400 $\mathrm{K}$, whilst the adiabatic flame temperatures for these mixtures lie between around $2700 \mathrm{~K}$ at $30 \mathrm{mbar}$ and around $3200 \mathrm{~K}$ at atmospheric pressure in this stoichiometric range. As soon as a surface is already present in the system, condensation can occur with relatively small super-saturation ratios. The effect can be the deposition of iron and/or iron oxides on the sampling nozzle, which will lead to a reduced nozzle aperture. By the same token, any iron that condenses on the nozzle can not be detected by any measurement equipment analysing the molecular beam, thus making MBMS not viable measurement technique for iron species under those conditions. Surely this condensation can also take place in part in the gas phase, leading to particle formation, which may deteriorate the measured particle size distribution.

\section{CONCLUSIONS}

The equilibrium calculations for propene/oxygen/argon and hydrogen/oxygen/argon gas mixtures seeded with 170 ppm iron pentacarbonyl or ferrocene have shown that both pressure and mixture composition have an effect of the iron intermediates that will form. The calculated profiles may aid the design of future laser diagnostics studies by helping to find conditions with relatively high concentrations of iron species in the gas phase, such as $\mathrm{Fe}, \mathrm{Fe}(\mathrm{O}) \mathrm{OH}, \mathrm{Fe}(\mathrm{OH})_{2}$ or $\mathrm{FeO}$.

For the case of the condensed iron species, lowering the pressure will reduce the temperature below which they can be expected. But even at pressures as low as $30 \mathrm{mbar}$, solid atomic iron may be present until temperatures of $1600 \mathrm{~K}$ and above. This is well above the temperature of, for example, a sampling nozzle for molecular beam mass spectrometry. Hence, MBMS techniques are probably not viable, or at least problematic, for the detection of iron and iron intermediates from flames.

\section{REFERENCES}

[1] G. T. Linteris, and V. I. Babushok, "Promotion or inhibition of hydrogen-air ignition by iron-containing compounds," Procedings of the Combustion Institute, vol. In Press, Corrected Proof, 2009.

[2] G. T. Linteris, M. D. Rumminger, and V. I. Babushok, "Premixed carbon monoxide-nitrous oxide-hydrogen flames: measured and calculated burning velocities with and without Fe (CO) 5," Combustion and Flame, vol. 122, pp. 58-75, 2000.

[3] M. D. Rumminger, D. Reinelt, V. Babushok, and G. T. Linteris, "Numerical study of the inhibition of premixed and diffusion flames by iron pentacarbonyl," Combustion and Flame, vol. 116, pp. 207-219, 1999.

[4] G. T. Linteris, V. R. Katta, and F. Takahashi, "Experimental and numerical evaluation of metallic compounds for suppressing cup-burner flames," Combustion and Flame, vol. 138, pp. 78-96, 2004.

[5] T. Hirasawa, C. J. Sung, Z. Yang, A. Joshi, and H. Wang, "Effect of ferrocene addition on sooting limits in laminar premixed ethylene-oxygen-argon flames," Combustion and Flame, vol. 139, pp. 288-299, 2004.

[6] K. B. Kim, K. A. Masiello, and D. W. Hahn, "Reduction of soot emissions by iron pentacarbonyl in isooctane diffusion flames," Combustion and Flame, vol. 154, pp. 164-180, 2008.

[7] C. Hecht, H. Kronemayer, T. Dreier, H. Wiggers, and C.Schulz, "Imaging measurements of atomic iron concentration with laserinduced fluorescence in a nano-particle synthesis flame reactor," Applied Physics B, vol. 94, pp. 119-125, 2008.

[8] J. Z. Wen, H. Richter, W. H. Green, J. B. Howard, M. Treska, P. M. Jardim, and J. B. Vander Sande, "Experimental study of catalyst nanoparticle and single walled carbon nanotube formation in a controlled premixed combustion," Journal of Materials Chemistry, vol. 18, pp. 1561-1569, 2008.

[9] K. Kuwana, and K. Saito, "Modeling ferrocene reactions and iron nanoparticle formation: Application to CVD synthesis of carbon nanotubes," Proceedings of the Combustion Institute, vol. 31, pp. 1857-1864, 2007.

[10] R. L. Vander Wal, and L. J. Hall, "Ferrocene as a precursor reagent for metal-catalyzed carbon nanotubes: competing effects," Combustion and Flame, vol. 130, pp. 27-36, 2002.

[11] M. J. Height, J. B. Howard, J. W. Tester, and J. B. Vander Sande, "Flame synthesis of single-walled carbon nanotubes," Carbon, vol. 42, pp. 2295-2307, 2004.

[12] A. Lamprecht, B. Atakan, and K. Kohse-Höinghaus, "Fuel-rich flame chemistry in low-pressure cyclopentene flames," Symposium (International) on Combustion, vol. 28, pp. 1817-1824, 2000.

[13] O. P. Korobeinichev, V. M. Shvartsberg, A. G. Shmakov, D. A. Knyazkov, and I. V. Rybitskaya, "Inhibition of atmospheric lean and rich $\mathrm{CH} 4 / \mathrm{O} 2 /$ Ar flames by phosphorus-containing compound," Proceedings of the Combustion Institute, vol. 31, pp. 2741-2748, 2007.

[14] H. R. Paur, W. Baumann, H. Mätzing, and H. Seifert, "Formation of nanoparticles in flames; measurement by particle mass spectrometry and numerical simulation," Nanotechnology, vol. 16, pp. S354-S361, 2005.

[15] K. Tian, Z. S. Li, S. Staude, B. Li, Z. W. Sun, A. Lantz, M. Aldén, and B. Atakan, "Influence of ferrocene addition to a laminar premixed propene flame: Laser diagnostics, mass spectrometry and numerical simulations," Proceedings of the Combustion Institute, 2009.

[16] D. G. Goodwin, "An open-source, extensible software suite for CVD process simulation," Chemical Vapor Deposition XVI and EUROCVD, vol. 14, pp. 2003-08, 2003.

[17] G. T. Linteris, V. D. Knyazev, and V. I. Babushok, "Inhibition of premixed methane flames by manganese and tin compounds," Combustion and Flame, vol. 129, pp. 221-238, 2002.

[18] G. T. Linteris, M. D. Rumminger, and V. I. Babushok, "Catalytic inhibition of laminar flames by transition metal compounds," Progress in Energy and Combustion Science, vol. 34, pp. 288-329, 2008.

[19] M. D. Rumminger, and G. T. Linteris, "The role of particles in the inhibition of premixed flames by iron pentacarbonyl," Combustion and Flame, vol. 123, pp. 82-94, 2000. 
[20] M. D. Rumminger, and G. T. Linteris, "The role of particles in the inhibition of counterflow diffusion flames by iron pentacarbonyl," Combustion and Flame, vol. 128, pp. 145-164, 2002.

[21] S. H. Bauer, and D. J. Frurip, "Homogeneous nucleation in metal vapors. 5. A self-consistent kinetic model," Journal of Physical Chemistry, vol. 81, pp. 1015-1024, 1977.

[22] A. Burcat, and B. Ruscic, "Third Millennium ideal gas and condensed phase thermochemical database for combustion with updates from active thermochemical tables," ANL-05/20 and TAE
960. Technion-11T, Aerospace Engineering and Argonne National Laboratory, Chemistry Division, September 2005.

[23] B. J. McBride, S. Gordon, and M. A. Reno, "Coeffcients for Calculating Thermodynamic and Transport Properties of Individual Species," NASA TM-4513, 1993

[24] P. Roth, "Particle synthesis in flames," Proceeding of the Combustion Instutite, vol. 31, pp. 1773-1788, 2007.

(c) Staude and Atakan; Licensee Bentham Open.

This is an open access article licensed under the terms of the Creative Commons Attribution Non-Commercial License (http://creativecommons.org/licenses/by-nc/3.0/) which permits unrestricted, non-commercial use, distribution and reproduction in any medium, provided the work is properly cited. 